\title{
O Momento Cultural como introdução de elementos estéticos na formação de profissionais no campo da saúde
}

\author{
The Cultural Moment as the introduction of aesthetic elements \\ in the training of professionals in the health field
}

Roberto Henrique Amorim de Medeiros (https://orcid.org/0000-0001-8224-9755) ${ }^{1}$

${ }^{1}$ Departamento de Saúde Coletiva, Universidade Federal do Rio Grande do Sul. Rua São Manoel, Rio Branco. 90620-110 Porto Alegre RS Brasil. robertoamorim80@ hotmail.com

\begin{abstract}
The core issue addressed in this article is in the context of the teaching practices of professional training at tertiary education level for work in the health field. After reflecting briefly on the problems of the privilege of the technique, the experience, and objectives of the proposal of the cultural moment are presented as the introduction of aesthetic elements in the training of undergraduate and graduate students in health. In the second part, the relations between art, culture and aesthetics used in this work are outlined and, from the experiences of more than a decade dealing with the proposal of the cultural moment in the classroom, the observed and potential formative effects based on the cultural moment presentations by the students are discussed. Lastly, the importance of aesthetic training for the updating of healthcare based on the discussion with classical and contemporary authors is stressed, and the cultural moment is proposed as an initiative for the introduction of aesthetic elements in the training of professionals in the health field.
\end{abstract}

Key words Cultural moment, Professional training, Aesthetics, Art, Culture
Resumo O recorte problemático abordado neste artigo está no contexto das práticas pedagógicas da formação profissional em nível superior para o trabalho no campo da saúde. Após refletir brevemente acerca dos problemas do privilégio da técnica, apresenta a experiência e os objetivos da proposta do momento cultural como introdução de elementos estéticos na formação de alunos de graduação e pós-graduação em saúde. $\mathrm{Na}$ segunda parte, situa as relações entre arte, cultura e estética utilizadas neste trabalho e, a partir das experiências de mais de uma década com a proposta do momento cultural em sala de aula, discute os efeitos formativos observados a partir das apresentações do momento cultural por parte dos alunos. Finalmente, argumenta acerca da importância da formação estética para a renovação do cuidado em saúde a partir da discussão com autores clássicos e contemporâneos e propõe o momento cultural como iniciativa de introdução de elementos estéticos na formação de profissionais do campo da saúde.

Palavras-chave Momento cultural, Formação profissional, Estética, Arte, Cultura 


\section{Introdução}

Harry Potter e a Ordem da Fênix ${ }^{1}$ é o quinto episódio da série de romances infanto-juvenis sobre a vida de um menino órfão com poderes mágicos. As aventuras e os dilemas da criança que chega à adolescência ao longo dos episódios são ambientados em uma Escola. A escola de magos é, portanto, o cenário da trama desse suposto romance de formação de nosso tempo.

No episódio citado, a Escola encontra-se sob diligência. Representantes de uma espécie de ministério mágico da educação são acionados para avaliarem os espaços e conteúdos responsáveis pela formação dos jovens magos. Após a avaliação, muitas mudanças de professores, de disciplinas, de conteúdos e de relações entre direção e alunos foram realizadas. Entretanto, a reforma da Escola a bem da formação mais apropriada, segundo a opinião técnica da gestão, encontra uma revolta. Um grupo de alunos passa a questionar as mudanças e a posicionar-se contra: "Precisamos aprender coisas que nos ajudem lá fora, na vida!"

Ao que parece, ficou inscrito em nossa história um desconforto semelhante aos acontecimentos de maio de 1968, especialmente na França. Uma revolta estudantil, entre outros fatores, resultante da insatisfação a respeito da formação universitária. Em 1968, aqueles estudantes franceses denunciavam a relação descontextualizada do discurso universitário com o contexto público e político de sua época.

Especialmente no decorrer do século XX o ensino passa a privilegiar como formação o adestramento técnico, efeito do discurso cientificista, dos avanços tecnológicos e das ditas exigências do mercado de trabalho. Desse modo, nem o interesse pela formação política e muito menos por algum aspecto da formação estética dos alunos, a não ser no campo específico das artes, se mantêm frequentes nos projetos pedagógicos de cursos de ensino superior, técnico ou médio.

O cenário não é diferente nos cursos superiores e técnicos da área da saúde. Entretanto, a crítica das práticas de gestão e atenção da saúde, impulsionadas em nível nacional pelo processo da Reforma Sanitária e, em nível mundial, no compasso das Conferências Internacionais de Promoção da Saúde ${ }^{2}$, ambos a partir do final dos anos 1970, implicam reordenamentos no campo da formação e da participação cidadã na produção da saúde, da doença e da qualidade de vida. $\mathrm{O}$ cuidado com a formação política do profissional em saúde responderia à demanda constitucional da responsabilidade de participação na gestão do
Sistema Único de Saúde (SUS), no caso brasileiro. E, sem dúvida, além do aspecto puramente técnico, a observância de uma formação estética para os profissionais da área da saúde seria bemvinda para cumprir com as expectativas da produção de conceitos e práticas de saúde que não se esgotam no registro biológico.

O presente artigo procura contribuir com o debate sobre a formação do profissional em saúde a partir de uma crítica a um dos aspectos da sua medicalização, especificamente no que tange ao privilégio da técnica em detrimento da ética das propostas formativas. Realizará a tarefa estabelecendo o campo problemático da atenção e do cuidado em saúde não medicalizados, discutindo o potencial da formação estética e suas relações contemporâneas com a arte, a cultura e a sociedade, apresentando e analisando os efeitos do Momento Cultural (MC), como ensaio de uma iniciativa acadêmica de fomentar a presença de um componente estético mínimo na formação do futuro profissional em saúde.

\section{Formação profissional em saúde: a técnica e a ética}

Quais seriam as principais novas exigências para o preparo profissional no setor da saúde? A partir da abertura política e da reforma no campo específico da saúde, o processo de produção de cidadania para o povo brasileiro, embora lento, acabou produzindo novas mentalidades. $\mathrm{O}$ usuário dos serviços do SUS, ou seja, potencialmente toda a população brasileira se torna mais exigente e participativa, seja no consultório privado ou nos conselhos públicos de saúde 3 . O discurso reformista pautado especialmente nas diretrizes de participação, integralidade do cuidado, além da equidade e da universalidade do acesso ${ }^{4}$, indica uma série de competências que extrapolam a simples manipulação técnica de determinada área especializada do conhecimento em saúde. Hoje, espera-se que o profissional, além do domínio de seu campo de saber, também tenha capacidade de lidar com a integralidade dos problemas de saúde, o que excede a identificação de patologias e atribuição de terapêuticas. Deve, no entanto, proceder ao ato de cuidado integral sabendo trabalhar em equipe multiprofissional, prestando escuta e olhar ampliados, produzindo vínculos duradouros com seus pacientes para o cuidado longitudinal, construindo projetos terapêuticos singulares, agindo no sentido da humanização dos serviços e desenvolvendo sensibilidade suficiente para saber trabalhar com a 
alteridade, o que implica o respeito às diferenças culturais, políticas e subjetivas ${ }^{5}$.

Parece claro que a racionalização técnica não cumpre a tarefa da formação integral do novo profissional em saúde. Nem mesmo parece ser suficiente, embora bastante louvável, que junto à formação técnica haja espaços privilegiados para a formação política - a construção subjetiva de cidadania - daquele profissional. A essência da mudança, dadas as expectativas de novas competências, parece estar muito mais na acentuação de elementos para uma formação ética do que a tecnicização e disciplinarização das tecnologias leves $^{6}$ ou mesmo a repetição da técnica desde a graduação até a pós-graduação, ainda que com ênfase na prática, como é o caso dos programas de Residência.

De modo análogo à ênfase do papel formativo da Universidade na construção da reflexão e do pensamento lógico, os programas extra-acadêmicos de treinamento em serviço e sob supervisão, outra denominação das Residências, também objetivam o ensino do saber, do fazer e da produção do saber-fazer do profissional em saúde. A diferença está precisamente naquilo que o segundo tem por objetivo: resgatar uma formação que responda positivamente à competência exigida do profissional em saúde e que, ao que tudo indica, não é atingida apenas pelo cumprimento do currículo mínimo das graduações.

A Residência constitui espaço e tempo valiosos para que o profissional adquira experimentação e desenvoltura na prática de seu ofício. No entanto, além do privilégio da prática que promove a capacitação técnica e eficiente sustentada no fazer, esse dispositivo de formação apenas desequilibra o fiel da balança, que anteriormente repousava sobre o pensar. Minha experiência como preceptor de uma Residência Integrada em Saúde, papel que desempenhei por oito anos, permitiu-me lidar com a formação de médicos, odontólogos, enfermeiros, assistentes sociais, farmacêuticos, nutricionistas, psicólogos e mesmo agentes de saúde, num contexto de integração entre pessoas diferentes, com variadas formações, advindas de ambientes acadêmicos distintos. Parecia claro o quanto o egresso da academia, ao fascinar-se pela dimensão do fazer, demonstrava menos interesse na reflexão crítica quando em contato intensivo com o campo do trabalho que o curso de Residência promove. Haveria uma continuidade à dissociação franqueada entre os espaços de formação acadêmica e o âmbito da produção no trabalho, entre o fazer e o refletir sobre e para a prática?
Por outro lado, também parece claro que a expectativa a respeito das novas competências há pouco listadas como desejáveis ao novo profissional em saúde dependam, em grande medida, do exercício da sensibilidade, do afeto, do compromisso ético, enfim, de uma formação em que o sentir e o pensar guardem relação de paridade para a construção de uma práxis. Não será essa disparidade no contexto das formações acadêmicas o que opera uma problemática acerca da incipiente qualificação do egresso para lidar com a complexidade do real com o qual sua profissão tem de lidar?

Minha aposta é afirmativa. A construção do sentir, do perceber a si e ao outro, do valor de racionalidades e formas de conhecimento como a poética, por exemplo ${ }^{7}$, potencializam recursos cognitivos e técnicos do profissional em saúde quando em contato com o território físico e existencial do outro e de seus distintos modos de levar a vida.

\section{O momento cultural: intenções premeditadas e efeitos inesperados}

Tirando proveito de fazer parte de um programa de Residência Integrada em Saúde no qual a reflexão crítica baseada na problematização era tão valorizada quanto as práticas do cotidiano nas Unidades de Saúde, um grupo de preceptores experimentou também propor o que ficou conhecido como Momento Cultural (MC), a ser realizado sempre ao final dos encontros semanais correspondentes à carga horária de formação teórica daquele Programa.

A proposta era bastante simples: nos minutos finais de cada encontro, um integrante do encontro teórico, frequentado por residentes de várias categorias profissionais, se comprometia em compartilhar com o restante do grupo alguma manifestação cultural ou artística que lhe agradasse. Podia ser de qualquer espécie, seja de um autor predileto ou algo de sua própria autoria, o que era particularmente estimulado. Embora houvesse uma intuição pedagógica, o propósito inicial dos preceptores fora apenas proporcionar um momento de leveza após um dia inteiro de trabalho físico e mental, tendo em vista que os seminários eram a última atividade do cansativo dia de um residente.

A suposta simplicidade inicial, inscrita pelo ato que objetivava apenas produzir leveza pelo compartilhamento de uma produção cultural, excedeu paulatinamente essa função quando a atividade se tornou sistemática e passou a pro- 
duzir agenciamentos imprevisíveis com efeitos para a formação. Ler uma poesia, executar uma música, mostrar um ensaio de fotografias, apresentar um vídeo para os demais colegas, além de provocar no outro uma reflexão, um sorriso, uma ideia, acabou aproximando relações entre os integrantes do grupo de residentes, permitindo que gostos comuns fossem reconhecidos, entrosando o trabalho em equipe, bem como auxiliando a realização de outras experimentações potentes na vida de cada um.

Importante ter em vista que a motivação devia ser espontânea e a participação voluntária. A resistência em participar do MC, que costumava surgir nos primeiros dias em que a proposta era remetida ao grupo, foi se dissipando no decorrer das semanas. A dificuldade inicial de eleger um voluntário se extinguia no compasso das primeiras participações. Um dos efeitos imediatos na dinâmica de sala de aula foi bastante evidente: no decorrer dos encontros a intervenção de um maior número de alunos nos debates em sala de aula se tornava significativa. Efeito importante se o objetivo do encontro pedagógico é a construção do conhecimento e não apenas sua transmissão.

No contexto daquela experiência de formação em Residência Integrada para profissionais em saúde, que tomo como caso, a contribuição do MC para o entrosamento do grupo de residentes foi inestimável. É desnecessário aprofundar a afirmação sobre os efeitos positivos do entrosamento para qualquer tipo de atividade que se realiza com o outro. Esse aspecto é identificado no momento em que as diferentes equipes que servem de cenário de práticas da Residência começam a ter notícias de que seu grupo de residentes passa a se encontrar em outros horários para momentos de lazer ou estudo, a despeito da elevada carga horária que já despendem juntos. A constituição de uma grupalidade é essencial para a realização conjunta de tarefas, o que inclui o trabalho integrado e em equipe no contexto da saúde. Na medida em que o diálogo passa a ser natural, a discussão de um caso, a construção de um projeto terapêutico singular, a consulta conjunta ou mesmo a disponibilidade para parcerias de trabalho no território são evidentemente facilitados.

No âmbito individual, a participação no MC parece ter o poder de conferir importância e sentido a determinadas práticas e habilidades desenvolvidas em outros tempos de vida daquele que agora foca todo seu esforço no treinamento para uma determinada função no campo profissional. O tempo, encurtado para qualquer outra ativi- dade que não seja trabalho, tem deixado poucas oportunidades para que o sujeito da produção no capitalismo neoliberal envolva-se em outras propostas de formação que não tenham valor de uso e de troca para garantir o sustento. Assim, quando consegue reservar tempo para o ócio, lhe resta o consumo de artefatos ou programas de lazer precários e quase nenhuma motivação para desenvolver potencialidades criativas.

Porém, em alguma época da vida, algumas pessoas ainda encontraram disponibilidade para desenvolver o canto, a dança, a música, o teatro e, com frequência, não mais encontram o sentido da inserção dessas habilidades no seu mundo atual. O MC parece também fomentar um sentido para algo que deveria ser óbvio: que os potenciais do corpo e do intelecto humanos são subestimados e subutilizados pela obediência ao imperativo de produzir capital incessantemente na sociedade neoliberal.

Além das possíveis contribuições para o processo pedagógico em termos de entrosamento, participação e desinibição, tornar público um prazer estético ou uma habilidade artística pode promover àquele que as expõe o estímulo para desenvolver outras possíveis expressões do seu potencial de vida, mesmo na sua função profissional.

\section{Manifestações artísticas e estéticas: manifestações da cultura.}

Há 6 anos atuando como professor universitário, tenho levado a proposta do MC também para os cursos de graduação afins à área da saúde. Neles, a apresentação de um vídeo contendo uma performance de dança, teatro e mesmo uma mensagem reconfortante ou motivacional, costuma ser relaxante ao final de um período relativamente longo de atenção concentrada do aluno. Por vezes, pode até ser angustiante o compartilhamento de um autor da literatura por meio de um poema ou prosa, de uma cena de cinema autoral, de uma obra de artes plásticas que, pela força de sua qualidade artística, proporciona ao aluno experimentar o contato com formas de transmitir conhecimentos, modos de vida e experiências diferentes do que estão acostumados pelos textos de artigos científicos, que mais os informa do que os forma. A busca não é necessariamente pelo efeito modulador dos ânimos, mas também pelo que leva o aluno a se posicionar e pensar no caminho para a casa.

É na oportunidade em que um colega se revela em sua habilidade artística que o MC atinge 
seus melhores efeitos. Pude presenciar apresentações verdadeiramente artísticas e outras cuja qualidade estava mais na habilidade motora do aluno. Composições próprias ou interpretações ao violão, saxofone, violino, são exemplos. Mostras de ensaios fotográficos e equipamentos de fotografia, performances circenses de malabarismo, controle e expressão corporal, assim como poesias e prosas interpretadas com a maior fidedignidade, pois era o próprio autor quem as lia, costumam trazer maior interesse ao público formado por colegas de curso que jamais imaginavam tal habilidade e poder de criação daquele colega que já conheciam há tempos. Importante observar que, independente da qualidade artística, quaisquer das intervenções tinham o poder de aproximar os alunos do conhecimento de obras ou manifestações culturais, e produzir experiências afetivas ou estéticas.

O cultural, o artístico e o estético, compõem uma constelação articulada de sentidos tanto no campo filosófico e científico, como no senso comum. Neste último, é entendida como o domínio da erudição, do qual poucos iniciados participam ou se interessam. Já no campo filosófico os sentidos se ampliam com a contribuição de autores importantes de diversas áreas do conhecimento.

No contexto da proposta do MC, os sentidos dessa constelação podem ser circunscritos do modo a seguir. Cultural não é entendido como atributo de sofisticação, sabedoria e educação formal, o que evita o uso classificatório de distinção entre pessoas que possuem ou não cultura. Assim como na antropologia social ou sociologia, cultura é entendida como aquilo que opera nas produções dos modos de vida e códigos relacionais compartilhados ${ }^{8}$. Artístico, é melhor tomado como domínio intelectual ${ }^{9}$, como necessidade e como componente da formação humana ${ }^{10}$, meio de produzir conhecimentos e efeito da cultura, o que responde pela sua constante mutação como conceito $^{11}$. Por fim, estético, entendido como a simples dimensão do sentir, do se deixar tocar pelo que o outro produz como presença, dádiva ${ }^{12}$ e experiência a partir de sua proposta para o MC, passando ao largo do critério de beleza ou adequação normativa.

O MC procura incrementar a formação ou abrir um campo de possibilidades dentre as quais pode figurar o início do envolvimento do aluno com a arte, seja como apreciador pelo estudo e interesse estético, seja como autor na medida em que dê vazão a uma habilidade ainda latente. Esses são os casos em que outros tipos de agenciamentos tomam a cena nos cursos de formação acadêmica, pois é imediata a aproximação entre colegas que compartilham de um mesmo gosto estético ou temático. O que se produz a partir daí é inesperado, mas com certeza guarda potência de criação e invenção de novos arranjos, seja no campo artístico, acadêmico, de trabalho ou de lazer. O que, como resultado, não parece ser pouco.

A atividade costuma compreender não mais que cinco minutos finais em cada encontro pedagógico. Entretanto, atribuir pouca eficácia a atos supostamente singelos seria render-se ao mundo subjetivado pela soberba científico-tecnológica e pela reificação do resultado como produtividade que se deixa quantificar e que se pode capitalizar.

\section{A formação estética e o trabalho em saúde}

A discussão sobre o papel da arte na Educação é vasta e excede aos propósitos deste artigo. Porém, não é incorreto afirmar que se espera da arte nas escolas a simples função de modular efeitos da racionalidade buscada como principal requisito da formação ${ }^{13}$. Um tipo de estética da sensibilidade para matizar efeitos da formação para a tecnociência ${ }^{11}$. Essa expectativa, entretanto, enfraquece o próprio potencial da arte na formação, pois além de assumir o equívoco de tomá-la fora do domínio intelectual, ela poderia bem ser substituída por qualquer outra atividade ou prática "moduladora", como a recreação, muitas vezes ocupada pela educação física - enfraquecendo-a também - ou o ensino religioso, por exemplo.

O resultado é inevitável. Ao invés da efetiva educação artística ou experimentação e expressividade com práticas que promovam a cultura, a civilidade ou a cidadania, o período concedido às artes acaba significado como "livre", desimportante ou recreativo, da perspectiva do educando. Até enfadonho, por vezes. Não surpreende que o anúncio de sua não obrigatoriedade na reforma do ensino médio não tenha causado reação contrária da sociedade brasileira em 2017.

Entretanto, cabe observar que o MC, ainda que não curricular e nem obrigatório, parece produzir efeitos significativos no processo de formação em saúde, o que o absolveria do julgamento apressado de desperdício do tempo acadêmico com inútil fruição hedonística. A arte contemporânea rompeu há tempos com a representação mimética da realidade. A arte não modula a razão. É no limite da racionalidade científica que a arte se mostra como outra racionalidade eficiente à tarefa de explicar o mundo, deixada incompleta por aquela. 
A partir dos anos 1930 o expressionismo nos brindou com uma arte crítica, cujo papel fora dar conta da reflexão acerca das experiências devastadoras em que século XX mergulhava a humanidade, com duas guerras mundiais entremeadas pelo nazismo ${ }^{14}$. A arte relacional, nos anos 1990, rompe com o estatuto de objeto contemplativo e convida ao experimento e à reflexão acerca da complexidade das novas formas de vida coletiva e individual ${ }^{15}$. Ambas rompem com uma função instrumental da arte.

O artista não cria por prazer, mas por absoluta necessidade de expressão ${ }^{10}$. É nesse ponto que a arte abandona o simples prazer estético e o discurso da beleza e passa a potencializar uma estética para o viver, consigo e com o outro. Assim, a estética extravasa o limite da arte para operar na constituição de uma ética para a vida, implicando os modos de nos conduzirmos no mundo, ou seja, o registro da política ${ }^{16}$. A construção de uma estética para o trabalho, fim de toda formação acadêmica, pode ser tributária da articulação estética patrocinada, por sua vez, pela arte e a cultura.

A ampliação do conceito de saúde a partir dos movimentos internacionais e nacionais que levaram à Reforma Sanitária no Brasil foi lembrado na abertura da VIII Conferência Nacional de Saúde, em 1986, pelo sanitarista Sérgio Arou$\mathrm{ca}^{17}$ ao ressaltar a dimensão do sentir. O elemento estético começava a ter lugar de maior destaque na mudança das práticas de saúde ao levar-se em consideração não apenas a singularidade da experiência com a doença, mas também o sentir o outro na relação de cuidado entre profissional e paciente.

Após algumas décadas de abertura política e de novas experiências de produção de saúde no contexto do SUS, o controle social e a cidadania passam a demandar formas diferentes de participação e cuidados em saúde, que exigem da formação profissional algo além do conhecimento técnico e da habilidade motora ou cognitiva de sua área específica. As capacidades para a escuta, para o trabalho em equipe, para o raciocínio clínico em diálogo com outros campos profissionais, passam a ter importância central nas práticas de saúde. Entretanto, essas novas capacidades não parecem poder ser desenvolvidas com a mesma lógica de formação tradicional dos cursos técnicos e superiores em saúde ${ }^{18}$. Como desenvolver a habilidade da escuta do outro ou do trabalho em equipe com diferentes racionalidades e subjetividades a partir dos dispositivos acadêmicos formais baseados em treinamento e memorização?
A Política Nacional de Humanização ${ }^{5}$ surge para fomentar novas atitudes e práticas mais sensíveis no processo de cuidados em saúde. Propôs o acolhimento, a gestão participativa no processo terapêutico, a clínica ampliada e o projeto terapêutico singular, entre outros, como vias desse redirecionamento. Ora, a educação estética presentifica a dimensão humana na formação ${ }^{19}$. O trabalho com a estética aguça e desenvolve os sentidos humanos. Por meio da dimensão estética entendemos melhor nossa cultura e podemos ser sujeitos muito mais ativos na sua produção, pois ela configura um código de símbolos ao mesmo tempo sensíveis e intelectuais.

A formação que inclui o estético parece ser uma saída promissora para o desenvolvimento de competências como aquelas do novo profissional da saúde, que jamais seriam produzidas em sala de aula com leitura de textos e realização de exames. A arte, a seu turno, não apenas desenvolve a sensibilidade, como também desarticula as percepções comuns por meio de seu potencial de transgredir códigos vigentes. Ambas características essenciais, respectivamente, para o cuidado integral humanizado e para romper com o paradigma da medicalização dos processos no setor da saúde.

Colocados os argumentos em favor da formação estética para a mudança de práticas no campo da saúde, o problema recairia na mudança do paradigma pedagógico propositivo de novas cargas horárias e espaços de aprendizagens reformulados. Ainda que fosse identificado o fundamento básico desta mudança na oferta de mais experiências sensíveis aos alunos, desde o encontro com a arte em sala de aula até a aproximação intensa com as realidades da vida nos espaços rurais, agrários e urbanos, adiantaria reformular projetos políticos pedagógicos (PPP) e perfil dos egressos, se o mundo se encontra capturado por um modo de produção que instrumentaliza o saber do trabalhador e o alija da condição de criar e inventar renovadas formas de trabalho?

Um dos ensaios de A dialética do esclarecimento, de Adorno et al. ${ }^{20}$, trata do que os autores chamaram de Indústria Cultural. Preocupados com a condição humana pós-nazismo, os autores pretendiam demonstrar de que modo os objetos de criação artística transformam-se rapidamente em mercadoria, cujo tipo de consumo é surpreendentemente massificado, e como a indústria cultural não apenas mercantiliza a arte, mas também legisla sobre os modos de apreciar o objeto supostamente artístico.

Como já fora mencionado, a essência da criação artística, após o expressionismo, é reali- 
zar a crítica da cultura e da sociedade em que é produzida. Esse potencial é esvaziado no mesmo momento em que seus objetos são massificados em termos de acesso e modo de consumo. Paralelamente, ao ter acesso e ser limitada a fruição da arte a um único modo consumista, o sujeito social experimenta a tutela e a falta de crítica quanto ao modo de vida em que está inserido, despotencializando a estética como ética. Toda estética passa a ser idêntica, qualquer que seja o lugar em que se produza, vide a arquitetura urbana das capitais, o shopping center, o estilo musical de sucesso que pauta as demais expressões musicais do momento, o roteiro repetitivo no cinema de entretenimento e o best seller. Tudo se reproduz em escala global independentemente do país, da língua ou da sociedade em que toma lugar. Enfim, essa ideia geral do ensaio $A$ indústria cultural, cujo subtítulo seria mais bem traduzido como $o$ esclarecimento como engano das massas, permite muitas reflexões acerca do sentido que assume a palavra cultural em nosso tempo.

Outra contribuição importante do ensaio citado é postular que o modo de vida patrocinado pelas sociedades industrializadas acabou por promover um tipo de categorização da massa populacional para as quais se direcionam específicos objetos culturais a serem consumidos. É nesse sentido que surgem os conhecidos públi$\cos$ A e B para os quais se produz, diferenciadamente, de folhetins a novelas, de teatro a cinema, de música e literatura a programas de televisão e revistas, ambos com distintos preços de mercado definidos a partir de uma estratificação de consumidores. Nessa concepção, há um objeto de consumo pré-determinado para cada indivíduo em seu grupo estatístico-mercadológico e que, conforme a categorização, cada um recebe uma produção cultural frente a qual deve se comportar do mesmo modo ${ }^{20}$.

A massificação do produto cultural e a estratificação dos sujeitos do mercado comporiam um conjunto de condicionantes que capturariam indelevelmente qualquer efeito de práticas formativas, mesmo que sustentadas em parte na formação estética? Poderia o MC ser um gérmen do que seria uma bem-vinda ação no sentido de um movimento em direção à formação estética, como elemento dialógico aos paradigmas de conhecimento ainda em vigor, como a religião, além do modelo científico?

\section{Instante da arte, tempo de est(ética)... momento cultural?}

Não se prepara para a fruição da arte nos ensinos fundamental, médio ou superior em muitos países como o Brasil. Essa é uma afirmação que pode receber alguma discordância: mas só podem ter acesso à fruição da arte os iniciados? Por que haveria de se ensinar como aproveitar da arte? Cada um não poderia expressar seus afetos e cognições de modo singular quando defrontado com um produto sublimado do gênio inventivo humano? Não seria o caso de democratizar a arte?

Os problemas estariam bem colocados, na medida em que se reflita com honestidade intelectual sobre eles. Como não concordar com a democratização da arte, o fácil acesso aos objetos criativos e aos meios de criação para todos? Não seria preventivo o ato de não formar o sujeito para aproveitar do objeto artístico para não o alienar ao discurso hegemônico acerca do que é a arte em dado momento histórico? Responderse-ia com outra pergunta: mas não fora a massificação e a mercantilização da arte o que produziu sua democratização em nossa cultura pelo efeito da industrialização dos países e suas relações de mercado e modos de consumo? A resposta a essa última pergunta é, fatalmente, afirmativa. E o efeito disso foi desastroso, bem sabemos.

A dialética entre a democratização e a elitização da arte precisa ser mantida se quisermos seguir construindo alguma crítica sobre o problema. A formação para que um sujeito possa fruir da arte é essencial na medida em que ele possa manter alguma autonomia de escolha e de construção singular de senso estético.

Constitui-se em problema antigo no campo filosófico a articulação do bem e do belo. Para os kantianos, a autonomia provém do exercício da razão que, independentemente de sua inclinação, determina a vontade do sujeito em escolher o que é bom. Os seus críticos, como Schiller ${ }^{21}$, procuram retirar a primazia da razão colocando-a no mesmo plano da experiência do belo e da busca da felicidade que, por sua vez, ao virem ao encontro da razão do sujeito, produzem a vivência do que se pode chamar de autonomia. O que poderíamos derivar disso, com vantagem para o encaminhamento de respostas ao nosso problema, são as decorrências de uma proposição: para tornar um sujeito racional é preciso que ele se construa, antes, como sujeito estético.

A elaboração acima coloca muitos problemas à proposta tecnicista de nossas graduações 
universitárias e das políticas de educação fundamental e média. Sem espaços para que o sujeito desenvolva seu potencial sensível - um olho não enxerga e um ouvido não escuta, se não forem sensibilizados para tanto - o advento da racionalidade no sujeito se dá alienado da realidade do laço social do qual faz parte. A técnica e o uso da tecnologia, bem o sabemos, podem ser automáticos. Para bem operar com ambas não se faz necessário o raciocínio crítico, a reflexão política e o posicionamento ético sobre o ato. Basta apenas o adestramento. Aí está um bom caminho de pesquisa sobre a autonomia ou a automatia na sociedade contemporânea. Entretanto, autonomia, liberdade e felicidade viriam da aposta na laicidade do conhecimento, na dessacralização dos valores religiosos e da crítica de todo tipo de preconceitos ${ }^{11}$. Como não tomar como questão fundamental a formação individual e as propostas de construção da sociedade brasileira ao acompanharmos os atuais projetos políticos para nosso país, que chegam à proposta de limitar ou militar? $-\mathrm{o}$ ato pedagógico crítico do professor em sala de aula?

Eis a corroboração da tese que se construiu de Kant à Escola de Frankfurt, passando por Hegel e Marx. Apesar de contar com algum século de iluminismo e esclarecimento, que levariam a civilização à sua maioridade, liberdade e autonomia, a ascensão da burguesia acabou por ofuscar a dimensão emancipatória e potencializou a instrumental, tutelando intelectual e subjetivamente os sujeitos ${ }^{22}$. A cultura, ao mesmo tempo que liberta e autonomiza, como queria Kant, pode conformar e adaptar, como afirmou Adorno. A estrutura de conservação dominadora do poder nas sociedades capitalistas constrange o sujeito à adaptação aos seus modos de vida intrínsecos. E o papel da indústria cultural nesta adaptação já foi bem explicitado por Adorno e seus seguidores.

A beleza conceitual dessa teoria, entretanto, não apazigua. Se por um lado flagramos sua acuidade materializada nas escolhas de formas degradadas de arte ou de produções culturais da mídia para serem reproduzidas nos espaços do MC por parte dos alunos de curso superior, ela se torna imediatamente aflitiva, por serem escolhas daqueles que deveriam ser a elite cultural de nosso país, a saber, aquele indivíduo que chegou aos bancos acadêmicos superiores. Que as apresentações dos alunos reproduzam elementos da cultura de massa é o legítimo efeito da sua semiformação (Hallbildung) ${ }^{23}$ como produto sociopsíquico da indústria cultural. Pergunta-se: e quando alunos apresentam algo de sua autoria, como uma coreografia ou uma execução musical, estes seriam subprodutos da música e da dança possíveis de serem consumidas - ainda que se entenda no sentido de 'bem acolhida' - pelo restante do grupo? Seria um critério de escolha?

Para os propósitos do MC esse fato corriqueiro se torna algo preocupante, pois frente ao objeto cultural massificado e mercantilizado não há possibilidade de autonomia de pensamento e posicionamento crítico por parte do público. Um público que, sabemos, se sente desencorajado a procurar por si mesmo uma nova experiência estética sem que formadores de opinião, think tanks, publicitários, digital influencers, definam o que deve ser endereçado como bem cultural para cada um.

Identificar esse efeito no contexto de um grupo universitário ou já graduado é aflitivo, pois se supõe que na formação superior não haja apenas a repetição do mesmo - o que aproxima a ciência do dogma e, portanto, do modo de conhecimento da religião - mas que seja fomentado o espírito crítico, inovador e libertário do sujeito do conhecimento. Semicultura, nos termos de Adorno, é aquilo que produz sujeitos muito bem informados, mas sem condições de relacionar fatos e produzir opinião crítica sobre a questão ${ }^{22}$. A lógica dos mercados frustrou a expectativa kantiana da maioridade intelectual da civilização a partir do esclarecimento (Aufklärung).

É nesse contexto preocupante que alguma iniciativa na linha da educação estética necessitaria ser, sempre que possível, implementada em processos formativos. Quais as formas, os métodos, as apostas pedagógicas que dariam conta da tarefa?

Diante dessas distintas perspectivas, o que poderia constituir um processo de formação estética? Bastaria proporcionar aos docentes a ida a museus, cinemas e concertos como atividades isoladas, ou complementares ao contexto educacional? Que tipos de atitude algumas visitas isoladas a instituições culturais poderiam proporcionar? O que realmente é buscado em pesquisas que reforçam iniciativas desse tipo? O aprimoramento do gosto? O refinamento de certas sensibilidades voltadas apenas para si mesmo? A pura decifração de obras artísticas? ${ }^{16}$

Ainda que de modo incipiente, a iniciativa nomeada de MC para cursos em áreas afins à saúde, apresentada neste artigo, procura contribuir com a questão. Embora não tenha sido formalmente prevista nos PPPs, seja dos cursos de graduação em que é fomentado, seja do curso específico de pós-graduação em situação de Residência em Saúde mencionado no início deste artigo, o MC 
oferece uma iniciativa e uma contribuição inicial a respeito da formação da sensibilidade e abertura ao outro por parte dos profissionais em saúde que, cada vez mais, são instados a desenvolverem sua prática na dimensão do sensível, de modo humanizado, atencioso às singularidades, respeitoso das diferenças e acolhedor do sofrimento do outro. Para tanto, os profissionais desta área necessitam servir-se, não apenas de seu saber técnico, mas de certo não saber ético sobre a experiência do adoecimento alheio, o que sugere uma boa dose de habilidade de escuta e delicadeza afetiva.

A educação no sentido da autonomia é aquela que engloba a totalidade do ser humano. Eis o princípio implícito no termo Universidade. Nesse sentido, o MC como simples elemento do plano de ensino de uma disciplina ou, em uma situação ideal, a integração de uma sólida formação estética no PPP de um curso de graduação, parece poder não se limitar, em seus benefícios, apenas aos programas endereçados aos profissionais da área da saúde. A responsabilidade crítica com os modos de vida e sociedade produzidos e reproduzidos pelos atos profissionais e pelos efeitos de serviços prestados na sociedade, é tarefa de todo aquele que representa um determinado campo do conhecimento em suas práticas, seja da saúde, seja de outros setores.
A educação estética é caminho para a liberdade e para a autonomia. É preciso defender a vida humana em sua plenitude, pois parece insofismável que o potencial humano é muito mais diverso e rico para que um indivíduo apenas cumpra, na duração de sua existência, uma única função repetitiva e monótona. A falta de tempo para a fruição estética é sinal de um modo de vida que se reproduz com pouca crítica nas instituições geradas pelos sujeitos organizados pela lógica do discurso capitalista. O tempo exíguo que resta na vida de um indivíduo na contemporaneidade quando dele se deduz a produção no trabalho, a locomoção de ida e volta para casa, as atividades complementares da renda, mesmo nos finais de semana e feriados, transparecem ao senso comum que o gasto de tempo com o enriquecimento da cultura e com a fruição artística seja uma irresponsabilidade com a garantia do futuro e da própria vida. Resta saber, nesse caso, que qualidade de vida é proposta ou possível nas condições que o modo de produção capitalista gerido sob a ótica neoliberal tem nos reservado.

Será a preocupação com as exigências da vida, assim como manifestada pelos alunos da escola de magos, citada no início deste artigo, apenas o fruto de uma ficção literária juvenil? A literatura - a arte! - não explica uma parte da vida? 


\section{Referências}

1. Yates D. Harry Potter e a ordem da Fênix [DVD]. Los Angeles: Warner Video; 2007.

2. Buss PM. Promoção da saúde e qualidade de vida. Cien Saude Colet 2000; 5(1):163-177.

3. Ceccim RB. Invenção da saúde coletiva e do controle social em saúde no Brasil: nova educação na saúde e novos contornos e potencialidades à cidadania. Est Univers 2007; 33(1):29-48,

4. Brasil. Constituição (1988). Constituição da República Federativa do Brasil. Brasília: Senado Federal; 1988.

5. Brasil. Ministério da Saúde (MS). HumanizaSUS: política nacional de humanização: documento base para gestores e trabalhadores do SUS. 2a ed. Brasília: MS; 2004. (Série B. Textos Básicos de Saúde).

6. Merhy EE. Saúde: a cartografia do trabalho vivo. São Paulo: Editora Hucitec; 2002.

7. Bachelar G. A poética do espaço. São Paulo: Martins Fontes; 1989.

8. Da Matta R. Você tem cultura? In: Da Matta R, organizador. Ensaios de sociologia interpretativa. Rio de Janeiro: Rocco; 1986. p.121-128.

9. Dewey J. A arte como experiência. São Paulo: Abril; 1980. (Os Pensadores).

10. Deleuze G. Conversações. São Paulo: Ed. 34; 1992.

11. Favaretto C. Arte contemporânea e educação. Rev Iberoam de Educ 2010; (53):225-235. [acessado $2018 \mathrm{Dez}$ 14]. Disponível em: http://www.rieoei.org/rie53a10. pdf

12. Mauss M. Ensaio sobre a dádiva: forma e razão da troca nas sociedades arcaicas. In: Mauss M. Sociologia e antropologia. São Paulo: Cosac Naify; 2003. p. 183314.

13. Brasil. Lei no 9.394, de 20 de dezembro de 1996. Estabelece as diretrizes e bases da educação nacional. Diário Oficial da União 1996; 21 dez.

14. Machado CEJ. Um capítulo da história da modernidade estética: debate sobre o expressionismo. $2^{\text {a }}$. Ed. São Paulo: Ed UNESP; 2016.

15. Bourriaud N. Estética relacional. Buenos Aires: Adriana Hidalgo Editora; 2006.

16. Loponte LG. Tudo isso que chamamos de formação estética: ressonâncias para a docência. Rev. Bras. Educ. 2017; 22(69):429-452.
17. $8^{\mathrm{a}}$ Conferência Nacional de Saúde Sérgio Arouca parte 1. 1986. (09m39s). [acessado 2018 Dez 15]. Disponível em: https://www.youtube.com/watch?v=uWjYH5CSgv8\&t $=355 \mathrm{~s}$

18. Medeiros RHA. Residência Integrada em cenas: ensaios críticos acerca da formação do profissional em saúde. Porto Alegre: Rede UNIDA; 2016. (Série Vivências em Educação na Saúde). [Acessado 2018 Dez 15]. Disponível em: http://historico.redeunida.org.br/editora/ biblioteca-digital/serie-vivencias-em-educacao-nasaude/residencia-integrada-em-cenas-ensaios-criticos-acerca-da-formacao-do-profissional-em-saude -pdf/view

19. Melo de Amorim V, Castanho ME. Por uma educação estética na formação universitária de docentes. Edu. \& Soc. 2008; 29(105):1167-1184.

20. Adorno T, Horkheimer M. Dialética do esclarecimento. Rio de Janeiro: Jorge Zahar; 1985.

21. Schiller F. A educação estética do homem. São Paulo: Iluminuras; 1990.

22. Bandeira BS, Oliveira AR. Formação cultural e semiformação: contribuições de Theodor Adorno para pensar a educação hoje. Educ. (PUCRS) 2012; (35):225-232.

23. Adorno T. Teoria da semiformação. In: Pucci B, Zuin AAS, Lastória LACN, organizadores. Teoria crítica e inconformismo: novas perspectivas de pesquisa. Campinas: Autores Associados; 2010.

Artigo apresentado em 17/07/2018

Aprovado em 17/04/2019

Versão final apresentada em 19/04/2019 